\title{
Leadership in health: the concept and the need
}

\section{Vaidya A}

Abhinav Vaidya, MD, PhD, Associate Professor, Department of Community Medicine, Kathmandu Medical College, Kathmandu, Nepal.

\begin{abstract}
T eadership is not a bad word. I am saying this because leadership in today's times can often be taken in a bit of negative hue. A few may adore it for the power that comes with it, while a lot may abhor it, particularly in regards to the political imbroglio that the country's leaderships have given rise to. So, at the very onset, I must clarify that this article is not about politics or the political dimension of health. Indeed, it is difficult to disentangle medicine and politics, particularly if one is to nod to Virchow's view that 'Medicine is a social science and politics is nothing else but medicine on a large scale ${ }^{\prime 1}$. So, is it possible to envision the concept of leadership without thinking about the political aura that the word brings? It is difficult, but it is essential that we do so.
\end{abstract}

Leadership can be defined and described in different ways. It may be taken as the art of mobilizing others to want to struggle for shared aspirations ${ }^{2}$. It may be considered as the ability to get other people to do what they do not want to do and like it ${ }^{3}$. A leader leaves behind in others the conviction and the will to carry on ${ }^{4}$. Hence, leadership is partly a visionary endeavour, but it also requires correct attitude and flexibility to put the vision into action.

Leadership must be differentiated from management ${ }^{5}$. The essential component of leadership is vision, while management is more about execution. Nonetheless, the two often go together, or rather, it is better if they go together, i.e. present in the same person. Authority is the third angle of the triangle. Leadership cannot fully bloom in absence of authority. Further, leadership can be of different styles. Transformational leadership identifies the needed change and creates a vision to guide the

\section{References}

1. Mackenbach JP. Politics is nothing but medicine at a larger scale: reflections on public health's biggest idea. J Epidemiol Community Health. 2009;63(3):181-4.

2. Kouzes JM, Posner BZ. The leadership challenge. New York: John Wiley \& Sons;2006. change through inspiration, and is often associated with socio-political greats such as Gandhi and Mandela ${ }^{6}$. On the other hand, health sector, being a service sector, is often led by servant leaders who engage in intergroup collaboration to serve the mission of the whole ${ }^{7}$.

Leadership in health is of utmost importance. The enormous and diverse health issues which are often intertwined with many overarching social phenomena require leadership to come up with innovative ideas and visions to break the chains of comfort and convenience ${ }^{8}$. Having said that, leadership is not only about one megaperson or a superhuman that revolutionizes by making a discovery or invention, or brings in a radical change in health by his or her vision. Every health worker, irrespective of his or her specialty or position in hierarchy, is a potential leader, and must attempt to become one in his or her working milieu. For that, the leader must have some fundamental qualities such as the capacity to listen and empathize, to heal; have virtues such as awareness, persuasion, conceptualization, foresight, stewardship, and commitment ${ }^{9}$.

Nonetheless, one can always argue how much of these qualities are inborn and how much can be taught, giving rise to the perpetual debate whether the leadership is innate or acquired. While one can always take a side regarding this, there is growing evidence that leadership can be trained ${ }^{10}$. Therefore, attempts should be made to make the stakeholders of health aware of the concept of leadership, and its need. Instead of waiting for leaders to be 'born', the potential leaders must be actively sought and groomed- be it in clinical or public health setting, in academia or in research area ${ }^{11}$.

3. Gardner H . Leading Minds: An Anatomy of Leadership. New York: Basic Books;1995.

4. Bass BM. Bass and Stogdill's handbook of leadership: Theory, Research \& Managerial Applications. New York: Free Press; 1990.

5. Hersey $\mathrm{P}$, Blanchard KH, Johnson DE. Management of organizational behavior. New Jersey: Prentice Hall;1988. 
6. Bono JE, Judge TA. Personality and transformational and transactional leadership: a meta-analysis. J Appl Psychol. 2004;89(5):901.

7. Koh HK. Leadership in public health. J Cancer Educ. 2009;24(S2):S11-S18.

8. Koh HK, Jacobson M. Fostering public health leadership. J Public Health. 2009;31(2):199-201.

9. Spears LC. Practicing servant leadership. Leader to leader. 2004;2004(34):7-11.
10. Daniels J, Farquhar C, Nathanson N, Mashalla Y, Petracca F, Desmond $M$, et al. Training tomorrow's global health leaders: applying a transtheoretical model to identify behavior change stages within an intervention for health leadership development. Global Health Promotion. 2014;21(4):24-34.

11. Czabanowska K. Leadership in Public Health: reducing inequalities and improving health. Eurohealth incorporating Euro Observer. 201;20(3):28-31. 